\title{
Toward an Empirical Concept of Group
}

\section{LLOYD SANDELANDS and LYNDA ST. GLAIR}

What is to be made of the idea of "the group"? Is it a collection of personsliterally a gathering together? Or, is it something more-a real presence over and above its members? In unguarded moments, when the line is not held either way, the concept of the group may even flit between the two - involuntarily, and maddeningly, like one of those reversible figures in psychology textbooks that won't let the eye settle on a single image. This duality of the group - it seeming to be both a multiple of persons and a single entity - is a basic problem of the theory of the group.

This confusion about groups is deeply ingrained in language. Familiar words such as 'couple', 'group', 'collective', 'organization', and 'society' convey the idea, not just of multiplicity, but also of totality. The phrases ' $a$ couple' or 'the organization' convey the idea of a single entity. Other languages communicate an even more profound sense of the group as a primary fact - so much so that it is more difficult in them to convey the idea of a multiplicity. For example, the Melanesian and Micronesian languages employ personal pronouns as suffixes for the names of social relationships, and particularly of kinship. According to Levy-Bruhl (1931), the Melanesians:

... do not think in abstract terms, nor reflect upon concepts. They have never had any notion of the organic finality manifested by the structure and functions of the living body, nor of the special way in which the parts are subordinated to the whole, and the whole in turn depends upon its parts. Neither have they ever analyzed the solidarity uniting the individuals of the same family with one another. Nevertheless, their languages do testify that they do compare these. To them the familial group is a being which, by its unity, is like a living body. We too say: the "members" of a family, but to us it is a mere metaphor, though not.an inapt one. To them, although they do not think about it, it is the literal expression of a fact. (p. 266)

The confusion about the group is exacerbated by the fact that groups do not all appear the same way. Some really do seem to be multiples of persons. 
Individuals stand out and the group appears as an arrangement or structuring of them. Other groups do not seem to be constructions of this kind, but rather they seem to be integral wholes which submerge individuals within something larger. The difference can be seen, for example, in comparisons across cultures (Triandis, r 989). This is from Benedict's (1 934: pp. 97-103) classic analysis of the Plains and Pueblo Indians of North America:

The Plains Indians in all their institutions gave scope to the self-reliant man who could easily assume authority. ... their institutions fostered personality, almost in the Nietzschean sense of the superman. They saw life as the drama of the individual progressing upward through grades of men's societies, through acquisition of supernatural power, through feasts and victories. (pp. 97-98)

The ideal man of the Pueblos is another order of being. [There is an] . . insistence upon the sinking the individual in the group. In Zuni, responsibility and power are always distributed and the group is made the functioning unit. The accepted way to approach the supernatural is in group ritual. 'The accepted way to secure family subsistence is by household partnership. Neither in religion nor in economics is the individual autonomous. ... Sanction for all acts comes from the formal structure, not from the individual. (pp. 98-104)'

What is perhaps most interesting about this two-fold experience of groups is that it is not taken to be more of a problem. Although the human mind often resists dualities, there is something congenial about this duality. Few people care that the words for group refer ambiguously to a multiple and to a single entity, and except for an occasional social scientist, few worry the distinction." Nor does there seem to be much stumbling over the buried metaphor of "group members" (the metaphor seems to glide as easily through Western consciousness as through that of the Melanesians). Indeed, it seems that talk about groups is made easier by the ambiguity. Meanings can be altered as occasion demands, and conversation can proceed, even if parties have different ideas in mind. We believe that laxness about the duality of groups masks important questions about the existence and nature of group entities.

PLAN OF THE PAPER

Campbell ( $195^{8}$ ) observed that al though a group entity is implied in discussions of groups, this entity remains an empirical and theoretical enigma (see also, Moreland, 1987). This paper is an effort to develop an empirically grounded concept of group entity that can be used for scientific purposes. Our aim is to move the group entity from the realm of the hypothetical to the realm of the real, where it can be an object of study in its own right. 
We begin the paper by looking at how the group has been conceptualized. We review both classical and contemporary treatments of the group to find that it is regarded almost exclusively as a multiple, rather than as antity. As a result, the study of groups is burdened with problems of conceptualization that slow its progress. Next we consider Campbell's (1958) concept of 'group entativity' as a possible solution to some of these problems. We find, however, that instead of substantiating the group as an entity, the entativity concept identifies the group as an intellectual construction.

In the second half of the paper we review arguments and evidence for group entities. Although fragmentary, the evidence includes: I) first-hand reports of group entities; 2) indications that group entities have a different psychology than group multiples (suggesting functional differences between them); and 3) similarities across cultures in the conception and symbolization of group entities. Taking this material together, we discern five themes which substantiate the concept of group entity and distinguish it from the concept of the group multiple. Finally, we discuss implications of our analysis for expanding the scope of group theory and research.

THE GROUP AS A MULTIPLE

As noted by Campbell (1958), claims about groups - e.g., about their properties, structure, history, ecology, dynamics, or actions - are premised on the idea that groups exist. Nevertheless, the research on groups belies this idea. In psychology, there is a tradition of regarding the group as an abstraction - $\mathbf{a}$ will-o'-the-wisp having no concrete referent except to individual persons (see, Golembiewski, r970). There are few studies of group entities (but see Le Bon, I903; McDougall, IgI2), and these have been rebuked with charges of misplaced concreteness (Allport, I927) and anthropomorphization (see, Steiner, 1986). The same is true in sociology, where the mainstream also hews to an individual-centered concept of the group (Lee, I990), albeit more ambivalently (e.g., Homans, 1950; 1987; Turner \& Killian, I987) and notwithstanding efforts to conceptualize the groups as a 'social fact' (Durkheim, I896/ı932; Mayhew, I980). We contend that this bias towards the individual has limited the development of the theory of groups. Research must be directed at understanding groups both as collections of individuals and as entities.

\section{Definitions of Group}

Table I lists 16 well-known definitions of group. All focus on individuals and present the group as a multiple of individuals. Only one, by Lewin, speaks of the group as an integral whole; but this whole is soon identified with variously 


\section{Table I Definitions of Group}

"any number of persons engaged with one another in a single face-to-face meeting or series of such meetings." - Bales, 1950, p. 33.

"a convenient sociological designation for any number of people, larger or smaller, between whom such relations are discovered that they must be thought of together." Barker et al., I979, p. 8.

"acting together, in a coordinated way at work, leisure, or in social relationships, in the pursuit of shared goals, the enjoyment of the joint activity, or simply furthering the relationship." - Argyle, I99 I, p. I5.

"a collection of individuals whose existence as a collection is rewarding to the individuals." - Bass, 1960, p. 39.

"an aggregate of individuals standing in certain descriptive (i.e., observable) relations to each other." - Brodbeck, I958, p. 2.

"a collection of individuals who have relations to one another that make them interdependent to some significant degree." - Cartwright and Zander, I968, p. 46.

"a group exists (has unity) to the extent that the individuals composing it are pursuing promotively interdependent goals." - Deutsch, 1968, p. 467 .

". . libidinal ties are what characterize a group." - Freud, 1922/1959, p. 4 I.

"a number of persons who communicate with one another over a span of time, and who are few enough so that each person is able to communicate with all the others . . . face to face." - Homans, I 950 , p. I.

"a dynamic whole based on interdependence rather than on similarity." - Lewin, I 948 , p. 184 .

"a number of people who interact with one another in accord with established patterns. ... one objective criterion [is] . . frequency of interaction. . . A second criterion . . is that interacting persons define themselves as 'members,' ... The correlative and third criterion is that the persons in interaction are defined by others as 'belonging to the group'" -- Merton, 1957, p. 285-286.

"the distinctive thing about a group is that its members share norms about something." - Newcomb, 195 I, p. $3^{8}$.

"a number of people who need each other to satisfy basic psychological and biological needs." - Ross, I 989 , p. 39 .

"a plural number of separate organisms (agents) who have a collective perception of their unity and who have the ability or tendency to act and/or are acting in a unitary manner toward the environment." - Smith, 1945, p. 227.

"a collection of individuals who perceive themselves to be members of the same social category, share some emotional involvement in this common definition of themselves,

continued 
Table I continued

and achieve some degree of social consensus about the evaluation of their groups and of their membership in it." - Tajfel and Turner, 1979, p. 40.

"a collection or set of individuals who interact with and depend on each other." Zander, 1982, p. I.

motivated individuals. Ten definitions mention interaction among individuals as a key element and three definitions mention member perceptions of 'groupness' as important.

The idea that groups are multiples is so established that reviews of the literature today hardly need to define the group. For example, in their review of the last ro years of small group research, Levine and Moreland ( 1990 ) offer not a single definition of the group. Yet, their focus on individuals is made clear by their emphasis upon issues about the composition of groups, conflict in groups, the parts individuals play in groups, and the effects of individual leaders on group performance. These authors do note a few studies of group responses to "exotic" environments, but these are dominated by concerns about individuals. Likewise, in the area of group performance, they find that the emphasis has been on "social loafing", an individually-based phenomenon.

Messick and Mackie (1989) reviewed the previous five years of research on intergroup relations. Here we might expect that the group would be its own figure. Yet, this possibility is dashed by the authors' very first sentence: "When people are judged, either singly or together, on the basis of group memberships, intergroup processes are involved" (p. 45). Groups are said to be perceived according to the presence of one or more shared characteristics of members, such as race or gender. A defining property of the group therefore is homogeneity. But homogeneity is a statement about a multiple of individuals about their similarities and differences - not about a group entity.

The concept in psychology that comes closest to conveying unity is 'cohesiveness'. Cohesive groups have a unified purpose, strong norms for behavior, a strong sense of identity, high levels of interpersonal liking, and a high tolerance for frustration and resistance to dissolution (Newcomb, I96I; Cartwright \& Zander, I968). In short, they have more 'groupness' than noncohesive groups. However, even though the cohesive group appears unified, cohesiveness itself is defined as a quality of group members. Writes Zander (1982):

The cohesiveness of an established group is the strength of members' desires to remain members. Cohesiveness increases as individuals become more attracted to the group and develop a greater wish to take part in its programs. (pp. 4-5)

Thus, in the name of cohesiveness, there is hint of a group entity, but also a swerve away from defining the group as such. 
Sociological writing about groups is more open in its conception of them. Turner and Killian ( 1987 ), for example, find that there is a place in sociological theory for both conceptions of group as a multiple and as an entity. "Neither the group nor the individual descriptive approach," they argue, "is inherently more error-free than the other. Each type of description completes the other. Which will be given priority depends on the purpose at hand." (p. I2) However, where the question is put about whether the group is a multiple or an entity, it is generally resolved in favor of the former (Taylor \& Brown, 1979; Tajfel, I 979). Comparing the actions of individuals alone and in groups, Brown and Turner ( $198 \mathrm{I}$, p. 40) write:

... the distinction we are drawing is not between individuals on the one hand and 'something else' on the other. Both inter-personal and group behaviour are the actions of individuals as F. H. Allport correctly pointed out. But in one case the actions are of individuals qua individuals, while in the other they are of individuals qua group members.

Granovetter (1978) also comes down on the side of viewing the group as a multiple, as have network theorists since (e.g., Freeman, I992). In these accounts the group is defined as the pattern of interactions of individuals. And finally, Alderfer (1987, p. 193) speaks of the need of professional clinicians in group therapy to decide between treating the individuals or treating the group (see also, Bion, 1959). But his example of an intervention upon the group (e.g., "The group might wish to examine why only the male members have been talking for the last ten minutes") focuses on members.

Finally, some writers give group entities a limited reality, but at the same time keep focus on individuals. The group is conceived as an appearance of the persons that comprise it (e.g., Allport, I962; Davis, I992; Schelling, 1978; Weick, I969). The group is said to 'emerge' as a macroscopic property of the interplay of individuals, somewhat as a melody emerges as a macroscopic property of the interplay of variously pitched tones. Although this allows conversation about groups to jump between individuals and group entities, it has proven not to be a sound basis for theorizing (see, Webster, 1973; Szmatka, I 989). To the contrary, it highlights the problem of defining the group entity which on this account has no more substance than that of a property or appearance. The idea of emergence sounds definitive, but it is more wishful than articulate about group entities.

\section{Problems}

The main problem with the concept of the group as a multiple is that it fails to distinguish between the group and the individuals that comprise it 
(Golembiewski, 1970). To return to an earlier and well-known example, Homans (1950, p. I) defined the group as "a number of persons who communicate with one another over a span of time, and who are few enough so that each person is able to communicate with all the others, not at secondhand, through other people, but face to face." Although straightforward and easy to operationalize, this definition is silent about what makes a group a group, as against a mere aggregate of individuals. The fact that people can and do communicate face to face does not give them identity as a group. There are cases which satisfy this condition which we might not want to call groups (e.g., people who ride the same bus to work every morning), and cases which do not satisfy this condition which we might want to call groups (e.g., a line of mountaineers scaling a granite face, a family). This criticism applies to all definitions of groups based on behaviors or attributes of individuals. Each is liable to exceptions for the same reason: namely, because such definitions do not define the group apart from the individuals that make it up.

The same problem can be seen in another way as well, in terms of the individual group member. If the group is more than a simple aggregate of persons, then the persons in it must take on some new quality or attribute in virtue of being in the group. However, when membership in the group is defined exclusively by behaviors or attributes of persons, then those persons are left as they were, unchanged and unilluminated. No new quality is conferred upon them for being in the group. Calling them 'group members' (to exhume our buried metaphor for a moment) does not call to mind anything about a larger entity of which they are a unique part, or to which they contribute. Rather, it announces only an incidental and superfluous fact about them - namely, that they are among others who behave in the same way, or who have the same attributes.

The concept of the group as a multiple is produced by two powerful and largely misguided impulses in social theory - one to reduce social entities to persons; the other to reify personal attributes or actions as social entities. These two impulses are responsible for much of the confusion in group theory today.

Reduction. Reduction deserves its bad name in social science when it is done without knowledge of the object being analyzed. Analytical reduction is a valid mode of explanation, but only when both part and whole can be observed. Otherwise, it is an empirically empty exercise in definition in which the parts define the whole.

In the absence of a clear view of the entity, reduction creates problems of identity (Sandelands \& Srivatsan, r993). There is no telling how parts and whole are related. For example, what happens to a group when the persons in it leave, or go home at night? And, what happens when they are replaced? Does it remain the same group? Further, what happens when replaced persons reconvene (as happens with baseball teams on Old Timer's Days, and is beginning to happen with old rock and roll bands)? Which is the real group? 
Related to this, there is no telling the boundaries of the group. What are the criteria for deciding whether a given person is part of the group? What about persons who "belong" to multiple groups? (see, Katz \& Kahn, I 966; Barnard, 1938). Can a person be part of a group even if he/she never interacts with other group "members"? These droll puzzles signal serious conceptual problems (see, e.g., Nozick, I98I), and coping with them requires a clear view of the group as an entity. It is not enough to know the qualities of parts, for these in no way indicate the qualities of the whole. As has often been noted (e.g., Mandelbaum, 1955; Mayhew, I 980; Szmatka, I 989; Webster, I 973), truly social facts - facts about group entities - cannot be reduced to facts about individuals.

The hazards of analytic reduction without a view of the object analyzed can perhaps best be seen in contrast to a case where the object is in view. Consider, for example, an ordinary pencil. This object could be analyzed as a multiple of atoms. However, for purposes of explaining what a pencil is and how it works, such an analysis would be absurd because details about atoms are mostly irrelevant to these qualities of the pencil. It is more pertinent to talk of the pencil in terms of its graphite filament, wood or plastic casing, metal band, and softrubber eraser. Compare this to the unknown group. There is no telling what are its relevant parts. To be sure, groups are made of persons (as pencils are made of atoms). But this does not mean that persons are its most intelligible or tell-tale parts. It might be better to talk of roles, or behaviors, or brain waves, or molecules as the parts of groups. As Warriner (in Stoodley, r 962: p. 36) points out:

... the proposition that groups are composed of persons tells us nothing about groups as such, but merely says that persons are characteristic of human social life. It describes a characteristic of groups as one kind of social life, but does not indicate the structural components that are involved in groups as a particular kind of unity and reality. ${ }^{3}$

Reification. Close cousin to reduction is reification, which can be seen as an illfated answer to the problems that result when the object under study is unknown. Whitehead (1924) described reification as the fallacy of misplaced concreteness. Allport ( 1962 ) described it as the fallacy of denoting an object as real which cannot be denoted. A group is reified when a multiple of persons is mistaken for a group entity.

A common way that the group is reified is by attributing to a multiple a quality or action that applies only to an integral entity - such as when a nation is said to declare war, or when a college is said to play a football game, or when Congress is said to pass legislation (Allport, 1962). 'Nation', 'college', and 'Congress' are hypostatized groups that are defined only by the facts that are attributed to them. A group is reified also when a multiple is identified metaphorically with an object such as a system, organism, or machine (see, e.g., Katz and Kahn, 1966; Galbraith, I977; Parsons, I95 I; Thompson, 1967). Such 
identifications imply that the multiple is an entity just like the object it is compared to. When properties of comparison objects are appropriated to an unknown group, the result is an unwarranted group entity.

When the group is reified, so are its actions and effects. This can be seen in theories of group processes of adaptation, natural selection, and choice. Such theories name processes without specifying their content. They are marked by the use of 'achievement verbs' (see, Ryle, 1949) such as 'adapt', 'select', and 'choose', which only point to the facts that they are intended to explain (i.e., adapting leads to adaptation, selection to selected groups, and choosing to group choices). Achievement verbs can be deceptive because by naming both the fact to be explained and the process that does the explaining they offer a semantic connection in place of an empirical connection. In theories of groups, these verbs become necessary when there is no known group to theorize about (Sandelands \& Drazin, I989).

Reduction and reification are problems because groups have been conceived almost exclusively as multiples. As we have tried to show, the research on groups has proceeded largely without an orienting view of the group entity (Lee, I 990; Steiner, I 986). This is somewhat like studying anatomy and physiology without knowing that there is an animal involved - an animal that has a habitat and a characteristic way of life. To understand the life of groups it is not enough to know about people, or even to know about their interactions and networks of communication and sentiments. It is necessary to know also how these things relate to the nature and conduct of the group entity.

\section{Campbell's Concept of Entativity}

One way to deal with the problem of defining a group is to turn it into a problem of perceiving a group. This makes it a problem that ostensibly can be studied in its own right. Campbell (1958) argued that the question of whether or not group entities exist should be abandoned in favor of the question of how they are perceived. According to Campbell, it is more useful to regard entity-ness as an attribute or aspect that aggregates of individuals are perceived to have in greater or lesser degree, rather than as a fact about some groups and not others. Writes Campbell:

Among actual or potential aggregates of persons, there are certain aggregates which meet criteria of being "entities," and other aggregates which do not. This distinction is capable of empirical representation. (p. 15)

According to Campbell, what makes the social aggregate an entity is the same thing that makes any other collection of elements an entity - namely, the fact that we perceive them as such. ${ }^{4} \mathrm{He}$ argues that perception is a logical process of 
inferring objects from relationships among parts. What distinguishes social entities from ordinary objects (what he calls "middle-sized" objects), such as a stone or laboratory rat, is only the obviousness and immediateness of the inferences. In the latter instances, the process is so automatic that we do not notice the cues and logic steps that go into making them. However, in the case of social entities, the cues and logic steps are "less solid, less multiply confirmed, of less sharp boundaries, and less hard" (p. I 7). Based on the early work of Wertheimer, Kohler, and other Gestalt psychologists on object perception in the visual system, Campbell offers four principles of group perception: I) proximity (people close together are more likely to be perceived as parts of a group; 2) similarity (people who are similar are more likely to be perceived as parts of the same group); 3) common fate (people that move together in the same direction, and otherwise in successive temporal observations, are more likely to be perceived as parts of the same group); and 4) pregnance (people forming a part of spatial organization or pattern tend to be perceived as part of the same group). Thus, according to Campbell, the difference between group multiples and group entities is quantitative rather than qualitative - one of degree rather than kind.

Variants of Campbell's reasoning can be seen today in studies of group categorization and social identity. These studies ask how individuals perceive groups and how they think about themselves and others in relation to groups (e.g., Bar-Tal, I990; Insko \& Schopler, I987; Knowles \& Bassett, I976; Tajfel \& Turner, I979; Wegner \& Giuliano, I982; Wilder, 1977). Knowles \& Bassett (1976), for example, found that subjects approaching a gathering of people at the entrance of a building were more likely to treat that gathering as a unit (by walking around it rather than through it to get into the building) when the gathered persons were physically similar to one another and when there was a large number of them. And Tajfel \& Turner (1979) reviewed several studies which showed that the simple fact of social categorization, even when based upon ad hoc and trivial characteristics of individuals (e.g., preference for Klee versus $\mathrm{K}$ andinski paintings), was enough to trigger discrimination between groups (e.g., as reflected in biased allocation of rewards). Following Campbell, the premise guiding these studies is that group entities exist as unitized collections of individuals, where unit-formation is an inference process in cognition or perception.

There are two main drawbacks of Campbell's concept of entativity that undermine it as a basis for the study of groups. First, the entativity concept rests upon an untenable model of perception, in which objects are inferred from relationships among their parts (i.e., proximity, similarity, common fate, and pregnance). Perception cannot operate this way, as Figure I demonstrates [from Palmer, 1975].

If asked what is pictured in Figure I a we would probably say that it is a face. If asked how we know that it is a face, we might answer - following Campbell 


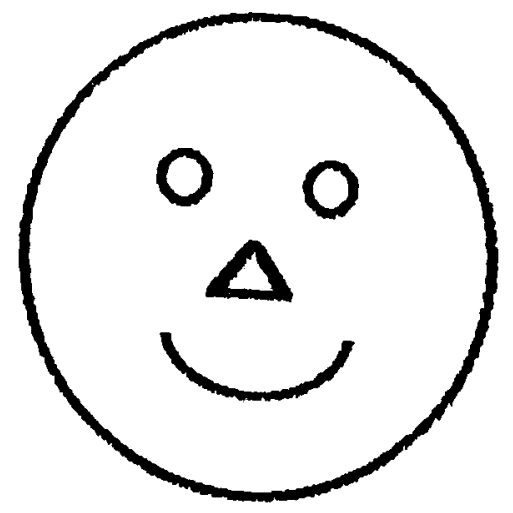

Figure Ia

\section{Figure $I b$}

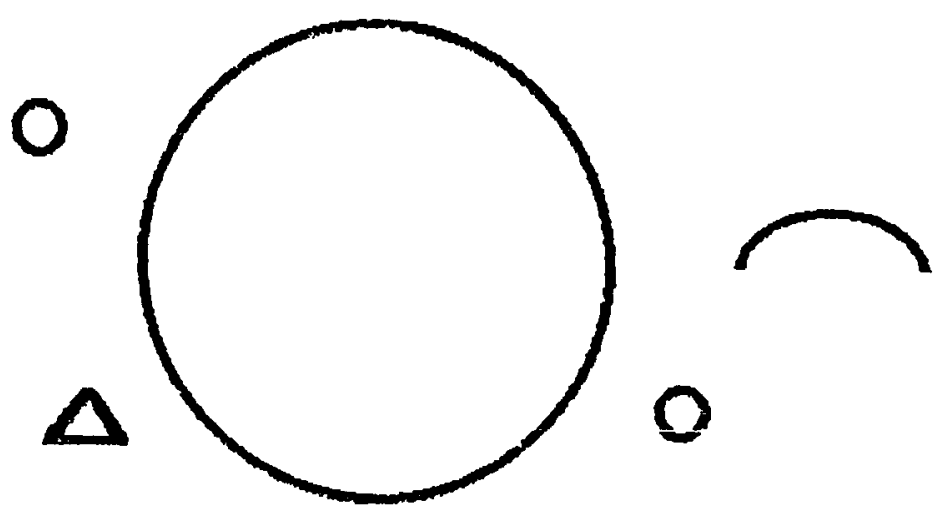

Figure I. The Parsing Paradox

- that we inferred this from the constant proximity of elements that are alike in being parts of a face (i.e., two eyes, a nose, a mouth, and a head). But compare this to Figure $\mathrm{rb}$. Here, we would be hard-pressed to say that this is likewise a face, despite the fact that it is equally a constant conjunction of face parts (i.e., two eyes, a nose, a mouth, and a head). What makes one set of parts a face and the other a meaningless collection? Notice that it is no use to say that Figure $\mathrm{r} b$ is not an aggregate of face parts (but an aggregate of geometric figures let's say), for this would mean that the parts of a face cannot be identified independently of their participation in the face as a whole. And this would mean that the face could not have been inferred from its parts. Thus, whereas it may seem that the whole is known from its parts, this cannot be the case. Indeed, the parts themselves cannot be known except with reference to the whole. 
The concept of entativity supposes that the group can be known from its parts; which in this case are persons. But as just demonstrated, this begs the question of how persons are known to be parts of the group - if not by prior knowledge of the group. This is a mistake of confusing a principle of analysis (i.e., that a group entity can be analyzed as a whole made of parts) with a principle of fact (i.e., that the group entity is a whole made of parts). The first principle is true, the second is not.

The second drawback to the entativity concept is that it is inherently unscientific. To be susceptible of scientific study, an object must have, or be presumed to have, an objective basis that is independent of the knower. The concept of entativity, however, denies such an objective basis by identifying the fact of the group entity with the fact of its perception - and with a narrowly conscious and verbalizable perception at that. The question of whether or not group entities exist is turned into the question of whether or not they are consciously perceived. Perhaps the latter question seems more open to study, more answerable, and less suspect philosophically (since it assumes nothing about reality). But it is a different question. And in respect to the study of groups, it is an unscientific question because it removes groups from the outer world of objects and confines them to an inner world of intellectual inference.

In these two ways, work in the area of social perception since Campbell ( 1958 ) steps aside of the questions of fact that we wish to address - namely, 'Do group entities exist in the world?' and, if so, 'Can they be investigated scientifically?'. Ours is a separate and historically older question of social psychology that is not identical to the question of how group entities could be inferred from perceptions of individuals.

\section{THE GROUP AS AN ENTITY}

This section presents arguments in support of group entities. It begins by reviewing three kinds of evidence for these entities. The first consists of firsthand reports of group entities. These reports are not equated with group entities (as if group entities needed only to be perceived to exist), but instead are taken to indicate group entities in fact. The second kind of evidence consists of findings that suggest that group multiples and group entities have different social dynamics and psychologies. They suggest that the difference between group multiples and group entities is qualitative, and not quantitative as Campbell suggests. The third kind of evidence consists of suggestions of a cultural basis for group entities, which appears as a tendency to symbolize group entities. Such symbols may make group entities salient to members and may make them easier to think about. Based upon these three kinds of evidence, we identify several common themes which together lead toward an empirical concept of group entities. 


\section{I) First-Hand Accounts}

People have intimations of group entities that they sometimes try to verbalize. Below we consider examples from members of a motorcycle gang, a well-known essayist, sports broadcasters, a basketball coach, social scientists, and biologists. Far from being a systematic survey, these disparate examples are offered only to suggest that experiences of group entities are widespread, even if conscious awareness of those experiences may be somewhat rare. Other examples, no doubt, could be added to the list.

Bosozoku Motorcycle Gangs. A primary activity of young Japanese motorcycle gangs, called Bosozoku, is participation in 'bosozoku' runs. A run consists of a large number of members racing as a group through the city. Sata (I988) has collected descriptions of this activity from many of its participants. These descriptions often portray the group, not as a collective, but as a transcendent entity. As one member describes it:

'Seventy to one hundred vehicles start their engines all at once. We can hear nothing but the exhaust noises. Nobody can, even the police cannot, stop us. . . . The moment the engines are started the disorderly crowd becomes a dinosaur. It's really overwhelming.' (p. 101)

\section{Another member put it this way:}

'When running, we are not in complete harmony at the start. But if the run begins going well, all of us, all of us feel for others. How can I say this? When, when we wag the tail of the band ... When our minds become, become one. At such a time, it's a real pleasure ... When all of us become one, I understand something ... All of a sudden, I realize, "oh! we're one" and think, "If we speed as fast as we can, it will become a real RUN." ... When we realize that we become one flesh, it's supreme.' (p. 1 13)

Montaigne on Friendship. In his well-known essay on friendship, Michel de Montaigne ( $1588 / 1949$ ) emphasizes the unity and indissoluble character of his friendship with Ettiene de la Boetie. Far from a casual acquaintance, this friendship melded two souls into a single indivisible entity.

For the rest, what we commonly call friends and friendships are nothing but acquaintances and familiarities, contracted either by some accident or by convenience, by means of which our souls are held together. In the friendship I speak of, they mingle and merge together with so complete a blending that they efface and can no longer find the seam that joined them. (p. 65) 
The unity marked off by their friendship is further indicated by its conspicuous absence of individual will or concern:

This [friendship] has no other model than itself and can be compared only with itself. It is no one particular consideration, nor two, nor three, nor four, nor a thousand. It is I know not what quintessence of all this mixture which, having seized my whole will, led it to plunge and lose itself in his; which having seized his whole will, led it, with equal hunger and emulation, to plunge and lose itself in mine. I may truly say lose since we reserved for ourselves nothing that was our own, nor that was either his or mine. (p. 66)

The "Amoeba Defense". When discussing the play of the University of Nevada men's basketball team during the I990 NCAA Championship Game, the television announcers referred repeatedly to its "amoeba defense" - a defense so named for its fluidity and tenacious envelopment of opposing players (who must have felt they were swallowed-up by something superhuman). This metaphor bespeaks a unity that is sometimes observed in athletic contests when a team operates with singular purpose and efficiency.

At times like these, coaches and players alike distinguish the group entity from the multiple of players that belong to it. The team is something over and above a collection of individuals, and this is reflected particularly in the quality of its play. In the former case, but not the latter, there is a sense of the players being "in a groove" and almost preternaturally "in tune" with their fellow teammates. Often this sense or feeling is accompanied by a level of peak performance where play unfolds instinctively based on subtle interactions and anticipations that are acted on even before registering in awareness. There is beauty in this as well, as suggested in these observations of one of the games premier coaches, Jack Ramsey (in Halberstam, i 98 I, p. 1 24):

What is this game that runs through my mind? It is a ballet, a graceful sweep and flow of patterned movement, counterpointed by daring and imaginative flights of solitary brilliance. It is a dance which begins with opposition contesting every move. But in the exhilaration of a great performance, the opposition vanishes. The dancer does as he pleases. The game is unified action up and down the floor. It is quickness, it is strength; it is skill, it is stamina, it is five men playing as one.

Moments of Communitas. Glimpses of group entities are sometimes reported in ceremony or ritual, or on other occasions of strong emotion or profundity. Turner (1974) describes the feeling of "spontaneous communitas", which is experienced as a source of power and as a sense of the group as an entity. $\mathrm{He}$ writes:

Is there any of us who has not known this moment when compatible people - friends, congeners - obtain a flash of lucid mental understanding on the existential level, when they feel that all problems (not just their problems), whether emotional or cognitive, 
could be resolved, if only the group which is felt (in the first person) as 'essentially us' could sustain its inter-subjective illumination [p. 79].

Writing along similar lines, Durkheim ( I 9 I 5 ) has remarked of a "collective life" which emerges sui generis in the heightened emotions which occur sometimes in religious gatherings. This phenomena of the group he called "collective effervescence":

Vital energies are over-excited, passions are more active, sensations stronger; there are even some which are produced only at this moment. A man does not recognize himself; he feels himself transformed and consequently, he transforms the environment which surrounds him [p. 422].

Group Entities in Biology. Although somewhat rare in social science, the idea of group entities is familiar in biology. The eminent entomologist, Wheeler, began talking about social insect colonies as organisms in the early r goo's. In his view, such colonies (e.g., ants, termites, honey bees) are "real organisms and not merely conceptual constructions or analogies" (Wheeler, r939, pp. 6-7). He based his argument on the many parallels between these colonies and organisms. Both maintain a unitary form through time and space, resist dissolution, and can be distinguished from others in their environment. Both are singular soma made up of individuated elements of germ plasm (cells in the organism, ants in the colony). And finally, both are functional unities having regulatory and restitutive mechanisms. In the ant colony, for example, if the queen dies, a worker develops ovaries and takes over the queen's place as the egg-layer for the colony. Thus, the same colony continues although the individual queen has been replaced. This is functionally analogous to the regeneration of cells in organisms.

According to Thomas (1974), Wheeler's view of insect colonies as organisms was popular from I9 I I until the early I950's, but it fell from favor because "nobody could figure out what to do with such an abstraction" (p. 149). It lacked the heuristic value required for its own survival. Today, however, the concept is back in fashion, and indeed is recognized as necessary for accounting for the behavior of social insects such as ants. As Holldobler \& Wilson (1990) note in their definitive work on ants, "The study of ant social organization is by necessity both a reductionistic and a holistic enterprise" (p. 3). Add to this the increasing difficulty that biologists have had in making hard and fast distinctions between concepts of organism and colony (entity and multiple). Even the cell, the paradigm example of an organism, is suspect. Margulis ( $198 \mathrm{I}$ ) has shown how the eukaryotic (nucleated) cell, the basic cell type for all plant and animal life on earth, must have evolved from communities of prokaryotic cells. The simple, unicellular amoeba turns out to be a complex community of microbes that work together for mutual benefit and survival. The 
picture emerging in biology thus is one in which concepts of both entity and multiple apply to all units of life.

Running through the foregoing accounts of group entities is the message that these groups differ from group multiples (i.e., a qualitative rather than quantitative difference). These groups are seen as distinct from the aggregate, as entities that are not multiples of persons. Such a description is possible only if the group is recognized in its own right; apart from the group multiple. And whereas the concept of entativity could account for a perception of a group entity, as Campbell describes, it cannot account for a perception of a group entity that is not a group multiple. The latter is a more sophisticated perception that cannot be explained by the laws of perceptual organization described by Campbell.

Finally, although the foregoing first-hand accounts may leave the impression that the concept of group entity is limited to extreme phenomena or to exceptional moments, we believe that the concept has general applicability, and that it is the conscious awareness of these phenomena that is limited to extreme phenomena and exceptional moments. Ordinarily the feelings which intimate the presence of group entities are insufficiently conscious or too fleeting to be reflected upon and captured in the pale of discursive self-report. What is remarkable about the accounts above, in our view, is not the existence of group entities, but the fact that sensitive observers identified them as a salient fact in the situation. In any event, the generality of group entities remains an unresolved empirical question.

\section{2) Two Psychologies of Groups}

While the reports above suggest that group entities are experienced as qualititatively distinct from group multiples, they do not establish the crucial theoretical claim that it is important to distinguish the two. As William James somewhere said, a difference that makes no difference is no difference.

The claim that group entities differ significantly from group multiples is suggested by evidence that the two types of groups have different psychologies and dynamics. Such differences can be seen in Milgram's (1974) research on modes of obedience, Janis' ( 1972 ) investigations of failures of group decisionmaking, Le Bon's ( 1903 ) studies of psychological crowds, and Blauner's ( 1964) analysis of alienation in business organizations, to name a few examples that are perhaps well known. A brief review of the work of these authors adds further plausibility to the claim that group entities and group multiples differ in substance as well as in appearance.

Milgram and the Psychology of Obedience. Among the best-known findings of social psychology is that obedience takes two discrete forms - one that involves 
a mental state of autonomy, in which people act responsibly as individuals; and another that involves a mental state of agency, in which people act irresponsibly as agents of a leader or authority (Milgram, I974). Milgram's experiments, it may be recalled, engaged subjects in what was ostensibly a study of the effects of punishment on learning. Subjects were asked to evaluate the learning performance of another person (actually a confederate of the experimenter) and to administer electrical shocks to that person when he/she made an error. The shocks were designed to appear, by degrees, more painful and more dangerous with each error. Setting aside a number of interesting details, Milgram's basic finding was that subjects, who at first may have acted on their own behalf, grew increasingly anxious and restive as the shocks became more severe. But only to a point. Beyond this point, subjects who remained in the experiment (i.e., who obeyed the experimenter's requests to continue) seemed to reconcile themselves to the task and to overcome whatever conflict they had felt about it. From this point onward, they acted (often strangely and mechanically) as the unresponsible agent of the experimenter. Milgram's most arresting finding may have been that not a single subject who came within 5 shocks of the end of the experiment failed to complete the experiment (despite the seemingly horrific consequences of the shocks to the person receiving them) (Milgram, 1974, p. 35).

Milgram concluded from his experiments that there occurred a definite transition in the dynamics of the social interaction, which he likened to a change of phase. Says Milgram: "I think of a state of agency as a real transformation; ... just as water can turn to ice under certain conditions of temperature, a person can move to the state I call agency" [in Meyer, I970, p. 132]. This transformation, according to Milgram, is not merely a quantitative change, rather it is a qualitative change that participants recognize and often try to resist. Again, in Milgram's words: “They even try to get out of it but they are . . . engaged in something from which they cannot liberate themselves. They are locked into a structure, and they do not have the skills or inner resources to disengage themselves" [in Meyer, 1970, p. 130]. This idea that obedience is a distinct condition of the dyad having its own form and dynamics is compatible with the idea of a group entity. Further, the change of phase in moving from autonomous actor to obedient agent could mark a change from a group multiple to a group entity.

Janis and Groupthink. A similar interpretation can be given to Janis' (1972) observations of the phenomenon of group decision-making that he called 'groupthink'. According to Janis, groupthink is a particular and pathological condition of group decision-making that arises in a cohesive in-group when concurrence-seeking becomes so dominant that it overrides realistic appraisal of alternative courses of action. It is an inversion of the usual effect of cohesiveness 
upon group dynamics. Whereas people ordinarily are more willing and able to share their views as they become more comfortable and friendly with one another, under conditions of groupthink, they are less willing and able to share their views. Instead, they strive to protect one another from dissenting views.

Janis (1972) argues that groupthink comprises a definite break and alteration in the psychology of the group. Defining this break, he argues, is a nondeliberate suppression of critical thought which manifests itself as a syndrome of illusions of group unanimity and invulnerability, and a belief in the inherent morality of the group. For some reason, and without intending to do so, group members stop thinking for themselves, and put their faith in the wisdom of the group instead. As in the example of obedience above, the concept of a groupthink group having unique psychological dynamics rests easily alongside the concept of a group entity that is qualitatively distinct from group multiples. Further, and again as in the example of obedience, the change in social psychology observed in moving from a non-groupthink group to a groupthink group may correspond to a change in the group from a multiple to an entity.

Le Bon and the Mental Unity of Crowds. One of the foremost observers of large groups was Le Bon (1903). His reflections on the nature and activities of crowds led him to suggest that crowds sometimes develop a psychology that is distinct from the psychology of individuals. In his preface to The Crowd (1903) he previews his most important insight:

The whole of the common characteristics with which heredity endows the individuals of a race constitute the genius of the race. When, however, a certain number of these individuals are gathered together in a crowd for purposes of action, observation proves that, from the mere fact of their being assembled, there result certain new psychological characteristics that differ from them at times to a very considerable degree.

Le Bon's argument for the identity of the crowd thus is based on its possession of unique characteristics that are not represented by individuals and cannot be inferred from individual characteristics. This is clear in his description of how crowds form:

Under certain given circumstances, and only under those circumstances, an agglomeration of men presents new characteristics very different from those of the individuals composing it. The sentiments and ideas of all the persons in the gathering take one and the same direction, and their conscious personality vanishes. A collective mind is formed, doubtless transitory, but presenting very clearly defined characteristics. The gathering has thus become what, in the absence of a better expression, I will call an organized crowd, or, if the term is considered preferable, a psychological crowd. It forms a single being, and is subjected to the law of the mental unity of crowds. (pp. $\mathrm{I}-2$ )

What really takes place is a combination followed by the creation of new characteristics, just as in chemistry certain elements, when brought into contact - bases and acids, for 
example - combine to form a new body possessing properties quite different from those of the bodies that have served to form it. (p. 6)

And finally, much like the biologists and their ant colonies, Le Bon compared the crowd to an organism. It is a comparison that he intended as an expression of literal fact, and not of mere simile:

The psychological crowd is a provisional being formed of heterogeneous elements, which for a moment are combined, exactly as the cells which constitute a living body form by their reunion a new being which displays characteristics very different from those possessed by each of the cells singly. (p. 6)

Blauner and the Alienated Worker. Completing our skein of observations about the two psychologies of groups - a cloth which runs from Milgram's dyads to Janis' small groups to Le Bon's crowd - we come finally to observations of alienation in industrial society. As described by Blauner ( 1964 ), alienation is a definite psychological condition or syndrome that arises from certain social and technical arrangements in the work place and that is characterized mainly by feelings of powerlessness, meaningless, isolation, and self-estrangement. This psychological condition, especially when compared to the psychological condition of craftwork, likewise suggests that there are two distinct psychologies of groups.

According to Blauner ( 1964 ), alienation is produced by work place arrangements that divide or fragment the individual from the social entity. Alienation results when a person's existence and consciousness are split into subject and object, when a person is sundered from the group and related to it as part to whole, when a person feels that he/she is in society rather than of society, and when a person's activity becomes a means to an end, rather than an end in itself. The paradigm example, well-known, is the automated assembly line. The typical factory worker is related to the work in essentially the same way as a machine (often by a design which treats the worker as one more factor of production, and necessary only and until his/her activities can be performed more efficiently in some other way). What results are movements and contributions that are specialized and stereotyped to limit their idiosyncrasy and thereby their subjectivity. At the same time, the worker is oriented primarily toward machines, and so is isolated from others who take positions elsewhere on the assembly line. This experience of the individual as alienated from the group entity may be contrasted with many kinds of craftwork where there is greater personal involvement in the work and more natural relations among coworkers. In these latter cases, where the individual is identified with the social entity, there arises a radically opposed psychology of self-actualization, belongingness, and meaningfulness. 


\section{3) Symbolization of Group Entities}

Finally, an indirect affidavit of group entities is the apparently universal need to symbolize them. In traditional societies, the clan was symbolized by its totem. In modern societies, the family is symbolized by the family name, sports teams by a name and sometimes a mascot, and business organizations by a name, logo, and even an advertising slogan. And, whether traditional or modern, almost all such groups celebrate themselves in myth or story. The pervasiveness of such symbols could not be coincidental, but must reflect a deep-seated urge (even a compulsion) to represent the group as an entity that is distinct from its individual members and that is distinct from other groups. ${ }^{5}$

Through symbolization, feelings of the group are given imaginable form typically that of an object or event that can be perceived, such as a totem, name, mascot, logo, story, or even a charismatic leader. The symbol offers an objective basis for conceiving feelings of the group. The symbol represents the group in a definite form that makes it more obviously real and thereby more discussable. The symbol thus differs from a sign, which does not embody its object in this way, but rather signals its presence by being paired with it. As Langer ( 195 I, pp. 26-52) points out, the symbol is what the mind uses to think with; it is the basic stuff of thought.

This view of symbolization is supported by the researches and writings of others who have investigated the relationship between the group and its symbols. According to Durkheim (1915), the totem of primitive societies functions as a rallying center for the clan and gives the clan a religious dimension. By expressing the experienced unity of the clan in material form, the totem makes that unity a present fact for members of the clan. Often, the totem is emblematic of one or more felt aspects of the clan (e.g., as a totemic animal might embody a clan's aggressive inclinations, or powers of survival; or as a totemic vegetable might embody a clan's spiritual identification with the land). By identifying the group with an integral and often living object or event, the totem affirms the integrity and vitality of the group, and provides a basis for group feelings and for thinking about the group in relation to other objects and events.

Writing about the psychology of the group, Freud (I 922/1959) theorized that its leader is the primary emotional object and symbol of the group. According to Freud, the primary mechanism of group formation is an instinctive emotional identification and bonding (libidinal cathexis) of group members to group leaders. An allied mechanism of group formation occurs as group members identify with one another as a result of their common libidinal cathexis to the leader. Through these mechanisms the leader-object is assimilated to the ego ideal and the leader is established as the emblem of the group.

And finally, Morocco (1979) has written similarly, though not directly in Freudian terms, about the emotional needs that are exercised and satisfied by 
stories about the group, and about the role of stories in symbolizing the group entity:

... group story telling can be understood [in part] as a process by which individual member's feeling about the group becomes transformed into collective conceptions of the group. The process begins with (I) members experiencing an uncertain, formless feeling; and continues with (2) the introduction of a private image by one member which expresses his/her feeling; (3) the diffusion and elaboration of that image by other members; and (4) the representation of member's shared view of the group in dramatic form, such as a story, joke, or game (p. i8).

These ideas are consistent with the suggestion above that group symbols are universal because they address a basic cultural problem. Namely, that of giving objective form to a wordless awareness of the group entity.

\section{Common Themes}

Although none of the foregoing anecdotes or arguments is by itself a convincing demonstration of a group entity, we believe that when taken together they suggest themes that point to a viable empirical concept of the group entity. We discuss five such themes below.

I) Supervening Qualities. The first-hand accounts of group entities, together with the evidence of their unique social psychology, call attention to supervening qualities of group entities that cannot be reduced to or described as qualities of its participants. The most definitive of these qualities is unity. This quality is suggested when a Bosozoku member refers to her gang as "one flesh", when Montaigne speaks of his friend and himself as a "complete blending" wherein it is not possible to "find the seam that joined them", when Le Bon identifies the psychological crowd as a "single being" subject to the "law of mental unity", when Wheeler remarks of the ant-colony as an organism, and when Blauner alludes to humane society as that in which the individual is not distinguished from the group as part to whole.

In many instances the unity of the group appears in connection with some other supervening quality. For Le Bon, the collective mentality of the group supervenes over that of its individual members (which, by comparison, is typically more subtle and responsible). Likewise, the fluid enveloping quality of the "Amoeba Defense" distinguishes the basketball team from its contributing members. Other authors say the same about the qualities of cohesion, mind, structure, rationality, group beliefs, locomotion, atavism, cruelty, stupidity, and even the sound of buzzing (e.g., Bar-Tal, I990; Kroeber, I 9 I 7; Mayhew, I980; Warriner, I956; McDougall, I 9 1 2; Sandelands and Stablein, I987). For many authors (but not all — see, e.g., Allport, I962), such qualities indicate the 
presence of a definite something beyond the individual - although they do not indicate precisely what that something is.

2) Changed Persons. Just as the group entity has qualities that distinguish it from a multiple of persons, the persons who constitute the group entity have qualities that distinguish them from the persons that constitute a group multiple. Milgram describes the unselfconscious and eerily robotic obedience of persons who act as agents of another person or a group. Janis traces a syndrome of illusions and uncritical thought that plague group members under conditions of groupthink. And, writing of the faces in the crowd, Le Bon and Freud note the disappearance of the conscious personality (with its inhibitions, restraint, and civility), and its replacement by the unconscious personality (with its impulsiveness, atavism, sense of omnipotence, irresponsibility, changeableness, credulity, and enthrallment to a leader).

3) Life-like Dynamisms. Group entities are dynamic, and remarkably life-like. One might almost say they are alive. According to one Bosozoku member, "The moment the engines are started, the disorderly crowd becomes a dinosaur" (emphasis added). Another speaks of "wagging the tail of the band" and of becoming "one flesh". In the realm of basketball, a defense is named for its semblance to an amoeba, and a game in its best moments is said to be a kind of dance. Durkheim describes religious ritual as a collective effervescence rooted in vital energies and active passions and sensations. And where the group entity is absent, as in Blauner's description of the alienated group, there is a loss of life, a spiritual and emotional deadening. And, not least, the biologists Wheeler and Thomas, and the anthropologist Le Bon, talk earnestly of ants, termites; and human crowds as organisms. Talk about group entities is full of images of life.

4) Directness. The first-hand accounts above suggest that the group entity enters awareness directly -- that it is comprehended all at once, in its entirety, and without reflection. It seems the group entity is really there, not as a figment of the imagination, nor yet as an inference about persons. In this respect, the group entity is like any other object of immediate awareness, such as a book or beer can or shoe. It is 'just known' and the knower cannot say how or why. This givenness of the group is reflected by the symbols that are used for it, which are as present as books, beer cans, or shoes (e.g. totems, names, leaders, stories). As Montaigne points out, to analyze an entity such as his friendship with Le Boetie as an amalgam of individuals is to misrepresent that entity and to mislead about how it is known.

In contrast to the direct awareness of group entities, perceptions of group multiples are indirect and require conscious effort to construct and justify. To see a group multiple requires an act of discernment that goes beyond simple seeing, and that combines perception and conception. First, a number of 
individuals must be observed. Then, those individuals must be classified together based upon one or more shared characteristics. Thus, to perceive a number of workers as a multiple might involve seeing that they are engaged in the same task, or that they are wearing the same uniform. Or to see a number of school children as a clique might involve knowing what tastes they share in common, or who talks to or has regard for whom. Far from being direct, unmediated, and unconscious, perceptions of group multiples are more complicated and contingent.

5) Knowledge Based in Feeling. Finally, whereas most things are known with little or no apparent feeling or involvement - save perhaps for the dim feeling of being conscious - it is different with group entities. The reports of Montaigne, Bosozoku members, Ramsey, Turner, and Durkheim are suffused with feeling, and betray an active, if not intense, involvement with the group in question. Likewise, the theories of the social psychology of group entities by Milgram, Janis, Le Bon and Blauner, suggest a prominent role for feeling - and in particular that the experience of a group entity feels different than the experience of a group multiple. Feeling may be the way group entities are known.

The examples of friendship and communitas especially, suggest that group entities are felt rather than simply seen. Although vision undoubtedly is involved, it is as part of the complex matrix of immediate bodily reactions in which feeling arises. Group entities are first known as feelings. Later, and upon a second look, they may be "reconstructed" as multiples of persons based on shared attributes of those persons. This view is reinforced by the difficulties observers have in describing them. Even the acute sensibilities and eloquent pen of Montaigne could not put in words the nature and basis of his sure and abiding friendship - which was for him a feeling beyond words. Asch (1952) refers to the feeling of the group as one of "atmosphere" and notes that it is both vivid and difficult to define (p. 225). As suggested earlier, from these difficulties arises the need to symbolize the group by objects or stories which can be visualized and turned over in the mind.

What does it mean to say that the group entity is felt? And what is the nature of this feeling? As Langer ( 1967 ) has pointed out, feeling is a phase principle. It is the way activity appears in consciousness when it has surpassed a threshold level of intensity. In Buck's ( $\mathrm{I}^{8} 8_{5}$ ) terminology, it is a 'read out' of ongoing behavior. This conception of how group entities are known is consistent with the suggestion above that group entities are life-like dynamisms rather than simple objects. Being dynamic, they must be known by a process that can represent the essential features of a dynamism. And being lifelike, this process must be one of feeling (see, Langer, I 967). This is the process that McDougall ( 1924 ) described as "the principle of direct induction of emotion by way of the primitive sympathetic response' (p. 24). As sensitive creatures, who are more or less 
attuned to what is going on around them, people can register and feel the dynamisms of the group in themselves. ${ }^{6}$

This view of how group entities are known is reminiscent of Levy-Bruhl's ( $1926 / 1985$ ) conception of the mentality of "primitive" peoples. The primitive mind, wrote Levy-Bruhl, does not experience the world atomistically in terms of distinct and logically classifiable 'things'. Rather, it experiences the world as an interplay of objects or events that embody or convey supernatural powers. These "mystical" objects and events are known, not by immediately given qualities or attributes, but by their felt participation in the dynamic matrix of everyday life. Whereas the percepts of the civilized mind are ordered logically and obey the 'law of non-contradiction', those of the primitive mind obey a different 'law of participation' which recognizes their active role in daily experience.

Interestingly, what was for Levy-Bruhl a development of culture, ${ }^{7}$ was for Freud a development of the ego. According to Freud (1930/1961), awareness of the ego (self) and of others develops from a single undifferentiated experience:

... originally, the ego includes everything, later it separates off an external world from itself. Our present ego-feeling is, therefore, only a shrunken residue of a much more inclusive - indeed, an all-embracing - feeling which corresponded to a more intimate bond between the ego and the world about it. If we may assume that there are many people in whose mental life this primary ego-feeling has persisted to a greater or less degree, it would exist in them side by side with the narrower and more sharply demarcated ego-feeling of maturity, like a kind of counterpart to it. (p. I5)

Thus, in Freud's thinking, the capacity to feel a group develops before the capacity to single out concepts of self (ego) and other. That the capacity to feel a group should come first is clear in the case of the developing infant who's survival depends upon union with others. According to Freud, this capacity is maintained in the mature ego alongside that of seeing group as multiples, and likewise for reasons that the adult depends on the group. ${ }^{8}$

In view of the examples given earlier, it is perhaps not surprising that Freud nominated the condition of 'love' as a paradigmatic and non-pathological example of the capacity to feel a group:

Normally, there is nothing of which we are more certain than the feeling of our self, of our own ego. This ego appears to us as something autonomous and unitary, marked off distinctly from everything else. ... There is only one state - admittedly an unusual state, but not one that can be stigmatized as pathological - in which it does not do this. At the height of being in love the boundary between ego and object threatens to melt away. Against all the evidences of his senses, a man who is in love declares that ' $I$ ' and 'you' are one, and is prepared to behave as if it were a fact. (pp. 12-13)

Finally, because group entities are known as feelings, one hesitates to classify 
them with other kinds of entities that are known as perceptions or intellectual judgments. Group entities do not have the same matter-of-factness as visually perceived entities. They can be recognized but not pointed to. And whereas knowledge of visually perceived things lends itself to verbal expression, knowledge of group entities seems locked in a bodily awareness that is beyond language. This invites the conclusion that group entities are less "real". But this conclusion confuses an epistemic point with an ontological point. That the group entity is known by feeling does not make it less of a fact; rather, it identifies it as the same kind of fact as a feeling. Group entities have the same logical form (dynamic, lifelike) as feelings; which is why they are known by feeling rather than by visual perception.

\section{The Concept of Group Entity}

Several ideas about group entities have been adduced. Group entities are: a) marked by qualities that supervene over individuals; b) comprised of persons who take on definite qualities; c) dynamic and life-like; d) known without reflection; and e) felt rather than seen. But what, at long last, do these ideas portend for a concept of the group entity?

One way to conceive of the group entity that is consistent with these ideas (and that in retrospect seems to be demanded by them) is as a form of life. This abstraction conveys simply and precisely its essential properties - its lifelikeness, its unique organic qualities, and its subordination of its participants to a dynamism. This abstraction also makes sense of the fact that the group entity is known directly (the human organism being naturally attuned to perceiving forms of life) and primarily on the basis of feeling (perhaps induced sympathetically, as described by McDougall).

In important respects, this concept of group entity recalls the concepts of group offered by Follett ( 1937 ) and Giddens (1 979). For these writers, the unity and identity of the group is rooted in its dynamisms. The group, they argued, is a process, not a thing. And as a process, it could not be inferred, but instead had to be felt or intuited. The group is more than a multiple of interacting persons, even though it can be analyzed as such. The present concept of group entity builds upon this view by adding the notion that it is the quality of life-likeness, in particular, that defines the group as an entity and distinguishes it from a group multiple. The vital animation of the Bosozoku gang and collective effervescence of a communal gathering differ fundamentally from the dreary mechanicalness of an assembly-line. The first are forms of life that define group entities, the last is a form of death that marks off alienated individuals.

The idea that the group entity is a living form poses formidable difficulties. "The status of life in Nature," wrote Whitehead (1934, p. 53), "is the standing problem of philosophy and of science." According to Whitehead, the very idea 
of 'a life' implies an individuality which appropriates myriad physical processes into a functioning unity. Life, he argues, is not a physical thing, but a process. It is an ongoing act of immediate self-enjoyment or self-realization; an 'occasion of experience'. A living form is a succession of these acts or occasions, extending from birth to the present in a single creative advance. However, conceiving of group entities in this way raises the problem of saying something definitive about them. What do you say after you have said that the group entity is a process? What is needed is a conceptual vocabulary that can be used to analyze these entities in useful ways. One such vocabulary has been suggested by Langer ( 1967 ), and it is worth a word or two here to point out a way that group entities can be studied.

According to Langer, the unity and vitality that distinguish living forms from non-living forms can be analyzed in terms of the special character of the elements of living forms and the dialectical patterning of those elements. Following Whitehead, Langer finds that the elements of living forms are not physical entities. They have not the character of things, but of acts or events. These elements are happenings within a continuous matrix of activity. As incorporeal acts, they are not literally objects, but have only a kind of virtual objectivity. While they can be recognized as distinct elements of an ongoing process, they fuse seamlessly into one another so that on close inspection it is impossible to say precisely where one act ends and another act begins. One act establishes the condition and grounds of another act which continues or completes the first. Every element of a life, says Langer, seems to emanate from the context in which it exists. Succeeding acts retain the character of preceeding acts, and the totality traces patterns of growth and development that are distinctive and definitive of living form. Langer further points out that the act elements which comprise living forms are interrelated in dialectical patterns. As act elements collide and interact they set up oppositions between and among themselves which define a dynamic system of tensions (tensive relations). These tensions and dynamisms among act elements are the empirical phenomena of living form; these tensions are known to observers as feelings.

Generalizing from Langer's concept of living form, we propose that group entities are living social forms which can be analyzed as act elements in tensive interplay. We propose further that group entities are known to observers by feelings that correspond to particular tensive patterns. Feeling is in the form of social life. Group entities are felt forms. Whatever the merits of this concept of group entity as living form, it is hoped that it will be permitted to stand as a kind of hypothesis until it can be adequately worked out. For now, it suffices to conceive of the group entity as a kind of vital form having the properties outlined above. 
We have tried to call attention to the group entity as a central element of social life. Judging from our own difficulties in doing so, we are not surprised that it has received little formal study. One feels insecure in talking about feelings of a group; and only partly because feelings do not lend themselves to words (Sandelands, 1988). It is easier and more respectable to talk about a multiple of persons that can be seen and pointed out to others.

That groups are almost exclusively regarded as multiples, rather than as entities, is perhaps because individuals are more compelling figures in perception than groups. Certainly, individuals are discerned more readily by the eye: they are distinct from other objects, and their parts are arranged invariantly and move together in a coordinated way. Individuals are wellsuited also to detection by the other senses - their voices, odors, and textures are perceived easily. ${ }^{9}$ In contrast, group entities are invisible to the eye and unobvious to the other senses as well. Rather, as we have seen, they seem to be known by feelings that extend beyond sense impressions.

This difference in sensory perceptibility is reinforced by cultural attunement to the individual. In the West especially, children learn early (often with immediate siblings) that a place in society is won in contest with other persons - which explains their fascination with others and fetish for comparisons. Viewed in this light, the group functions primarily as system for locating persons in a social order, thereby fixing their identity (Turner, 1985 ; Crocker \& Luhtanen, 1990). This function is more pronounced the larger and more differentiated the society - to the point, eventually, that groups are little more than backdrops in the drama of individual destiny (recall Benedict's example of the Plains Indians).

Culture influences perception by validating particular ways of seeing as "fact". Culture is the ground against which the figures of social perception are recognized. According to Warriner (1956, p. 552):

This stress upon the individual, upon explanations in terms of psychology or psychological processes, and upon the lesser reality and importance of the group and other social phenomena have become the sensible, common-sense point of view. Its acceptance does not need to be defended because it is common-sense and because its doctrines are congenial to a period in which there is a general cultural stress upon individualism and the importance of the person.

As long as common-sense holds that groups are multiples of individuals, then just so long will it interfere with awareness of group entities. The problem is compounded by the ease with which group multiples are defined. A multiple requires only a decision rule that includes certain individuals and excludes others. It could be persons who communicate face to face, or who are part of a 
common division of labor, or who like one another, or who share a place and time - the possibilities are innumerable. In contrast, to see a group entity requires the faith to trust feelings that are hard to fathom or articulate. This sort of faith is rare, even among those who are committed to group entities. Writers such as Durkheim, Simmel, Kroeber, and Mayhew, affirm that groups are social facts, but they have been unsuccessful in studying them as such. When push comes to shove, when ontology turns to methodology, they concede that only individuals can be observed and can be a basis for empirical study. In this respect at least, Durkheim's doctrine of methodological individualism betrays the insight that bore it. Justified by interest in social facts, it destroys them by reducing them to characteristics of individual persons.

Still, somehow, there seems to be something to the group. Despite its tradition of overlooking group entities, and despite its many frustrations over the years, the study of groups continues to flourish and to enlist the interest of new generations of social scientists. And though its core problems persist, they remain interesting and alluring. Evidently, something gives researchers cause to continue. We suspect that this something is the unspoken sense that the group is an entity. Probably this sense is little more than an intimation - an inchoate feeling that there is something there rather than nothing. For our part, we do not agree that the difficulties of coming to know group entities are reason to abandon them. To the contrary, we believe that these difficulties underscore the need to work harder to understand them and to find ways to talk about them.

\section{New Questions for Study}

The differences between group entities and group multiples suggest that there is a great deal about groups still to learn. In the wide differences between love and the multiple of marriage, or between communitas and a gathering in church, or between team play and variously motivated players, there is a gulf in understanding. Whereas the second of each pair is fairly well-understood, the first in each pair presents new questions for study. Little is known about the nature, ecology and natural history of group entities. Compare, for example, what is known about a simple multiple such as marriage with what is known about a simple entity such as a love relation. And, whereas it is relatively easy to observe and analyze marriages - e.g., to find out who gets married, how long marriages last, and under what conditions they dissolve - it is not easy to do the same with love relations (Martin \& Luke, I 99 I). Who can say who falls in love, or how long love lasts, or what are its relevant parts?

In addition to questions about the characteristics of group entities, there are questions also about the conditions under which they occur. It is not enough to ask 'What are groups?', we must ask also 'When are groups?'. For example, when will a gathering in church achieve communitas? And, for how long? How 
and why do certain multiples become entities? and certain entities become multiples? Are there discontinuities that mark the transition from one to another? Do these transitions correspond to phases, such as occur when a solid changes into a liquid? (see, e.g., Kroeber, I9I7; on viewing cultures as superorganic entities).

And then there are questions about the dynamics of group entities. What happens to these entities when members come and go? For example, are the Boston Celtics (a professional basketball team) the same team without Larry Bird (their retired star player)? Are they still a team? Or have they dissolved into a mere collection of players? There are dynamics as well pertaining to size and differentiation. What happens to group entities when they include a greater number of people? Or when members become more differentiated? Or when their internal structures change with the development of roles or sub-groups or sentiments? What happens to group entities when they come into contact with other group entities, or when they are required to share the same space? What happens when these entities compete, or cooperate, or merge? Although such questions are often asked of groups conceived as multiples, they are rarely asked of group entities.

Although rare in social science, answers to questions such as these can sometimes be gleaned from journalistic accounts of groups. An example is Tracy Kidder's ( I 98 I) chronicle of a computer design team, the Eclipse Group, that worked for a well-known manufacturer of mini-computers. Although largely a tale of organizational politics and intrigue, it is a story also about a work group that occasionally transcended its members in its quest to build a new mini-computer called 'Eagle'. In this story one can see the effects on the group entity of arrivals and departures of personnel, of intrusions by outside groups and managers, and finally of the self-destructive effect of the group reflecting upon its own success. Writes Kidder (p. 288):

Long before it disbanded formally, the Eclipse Group, in order to assist the company in applying for patents on the new machine, had gathered and had tried to figure out which engineers had contributed to Eagle's patentable features. Some who attended found the meetings painful. There was bickering. Harsh words were occasionally exchanged. ... Ironically, perhaps, those meetings illustrated that the building of Eagle really did constitute a collective effort, for now that they had finished, they themselves were having a hard time agreeing on what each individual had contributed. But, clearly, the team was losing its glue. "It has no function anymore. It's like an afterbirth," said one old hand after the last of the patent meetings.

From the standpoint of this paper, we may ask further if the success of the 'Eagle' development team was due to its operation as a group entity rather than as a group multiple. Such a conclusion, although at this point clearly tentative, is not inconsistent with the observations that have led us to hypothesize the existence of group entities. In fact, it is quite consistent with earlier examples 
(e.g., the NGAA championship basketball team). Thus another question we can ask is whether (or when) group entities are more effective at task performance than group multiples.

\section{Toward a More Comprehensive Study of Groups}

"To explain", wrote Durkheim (I9I5, p. 238), "is to show how one thing participates in one or several others". Usually, explanations take one of a few basic forms. A thing may be compared to an analysis of parts; or it may be compared to an analogue or metaphor; or it may be compared to a general category of things to which it belongs. All of these explanations operate the same way; each compares one way of looking to another way of looking.

For the study of groups, this suggests that once the existence of group entities is accepted as fact, then observed group entities must be compared to something else, such as multiples of individuals, or a system of roles, or, as suggested above, a dialectically organized system of acts. Indeed, this is what usually happens in everyday discussions about groups: the common person refers to groups as entities (e.g., the family, church, IBM, the United States, the University), and then proceeds to make sense of the group in terms of the qualities and behaviors of the people who participate in them. For many social scientists, however, these types of discussions rarely get off the ground because of the failure to accept the reality of group entities. Social science lacks a genuine concept of group entity. Thus, the literature is cluttered with footnotes to explain that when we say "the organization made a decision" what we really mean is that "the top managers made a decision". But if there really are no groups that amount to more than a multiple of individuals, then there is no reason to be concerned with anything other than individuals. Explanation must begin with the genuine article and then relate it to various analyses of parts. As Durkheim argued long ago, there can be no theory of groups unless there are group entities to theorize about.

The identification of (at least some of) the characteristics of group entities serves as a first step in developing methodologies for studying groups as entities rather than as multiples. Research toward this end must begin with the systematic identification and classification of groups as entities or multiples (or both). This process is facilitated by the characteristics that we have identified. Only when a sufficient sample of group entities has been discerned can we begin to find answers to our questions of "when is a group entity" or test hypotheses about differences between group multiples and group entities.

As one example, to test the hypothesis that task-oriented group entities perform more effectively than group multiples, observers could be asked to describe group interactions. Those descriptions could then be coded based on the five characteristics of group entities identified in this paper, and then the performance results of groups coded as entities could be compared against the 
performance results of groups coded as multiples. One potential problem, of course, is that cultural blinders may make it difficult for observers to see and express differences between the two kinds of groups. Nevertheless, we believe that the five characteristics of group entities are overt enough and substantial enough to produce a reliable operationalization of the group entity concept.

It remains then to compare group entities against conceptions of them as multiples. But this cannot happen until the elementary facts about group entities are discovered. When those facts are discovered, the need will arise to explain them, often perhaps in terms of facts about individual members. In this way, theories of interpersonal behavior may be helpful for explaining certain facts about group entities - such as why some groups grow large while others remain small; why some groups live longer than others; or why two groups cannot occur in the same place at the same time. Conversely, there will also arise a need to explain facts about individuals in terms of facts about group entities. In this view, questions may be asked about how group entities constrain or influence the people in them.

This paper has provided diverse evidence for the existence of group entities. We have identified some of the fundamental characteristics of these entities and have advocated using these characteristics to begin identifying group entities for study. We have observed that the performance of group entities and group multiples appears to differ, suggesting some practical as well as theoretical implications for this research direction. We hope that this paper leads to a resurgence of interest in understanding group entities. Macro-micro linkages are becoming more important in research on social behavior. It seems only fitting that these linkages be considered at the level of the group, where both individuals within groups and groups in their own right play a vital role.

\section{Lloyd Sandelands and Lynda St Clair}

Department of Psychology

University of Michigan, Ann Arbor, Michigan, $48108-1346$

\section{ACKNOWLEDGMENTS}

The authors thank Jane Dutton, Debra Meyerson, Mike Pratt, Anat Rafaeli, Mary Tschirhart, Jim Walsh, Karl Weick, the editor, and reviewers of this journal for their contributions to this work. Please address all correspondence to Lloyd Sandelands, Department of Psychology, University of Michigan, 58o Union Drive, Ann Arbor, Michigan 48 rog-1 346.

\section{NOTES}

1 This comparison of Indian cultures mirrors those drawn today between Western and Eastern Cultures. For example, it is said of the United States that its culture is a by- 
product of the character of its citizenry (hence, the metaphor of the melting pot), whereas of Japan it is said that its culture and national character transcend its individual citizens, who are subordinate and a by-product of its powerful influence.

2 There seems to be a generational quality to this worry. Every 10 years or so the problem of conceiving groups is taken up again, but left without a final resolution (see, e.g., Kroeber, 1917; Allport, 1927; Benedict, 1934; White, 1947; Campbell, 1958; Warriner, I956; Webster, 1973; Alexander, Geisen, Munch \& Smelser, 1987; Allison \& Messick, 1987 ).

${ }^{3}$ From time to time it is suggested that persons are not parts of groups. H. White (1992), for example, argues that the identities that constitute organizations are not necessarily persons, but rather may be any source of action that is not explicable from biophysical regularities, and to which observers can attribute meaning. And writing for a previous generation, L. White (I947) argued that group life is defined by its culture, which is a continuum of interacting elements which are not persons, but rather sentiments, ideas, and images:

Thus, paradoxical though it may seem, the proper study of mankind turns out to be not Man, but Culture. The most realistic and scientifically adequate interpretation of culture is one that proceeds as if human beings did not exist.

${ }^{4}$ See von Frisch (1962) for a like-minded account of social groupings among animals, and particularly of insects such as ants, termites, and bees.

${ }^{5}$ Campbell (1972) and others speak of this as a central element of mythology:

This recognition of mortality and the requirement to transcend it is the first great impulse to mythology. And along with this there runs another realization; namely, that the social group into which the individual has been born, which nourishes and protects him and which, for the greater part of his life, he must himself help to nourish and protect, was flourishing long before his own birth and will remain when he is gone. That is to say, not only does the individual member of our species, conscious of himself as such, face death, but he confronts also the necessity to adapt himself to whatever order of life may happen to be that of the community into which he has been born, this being an order of life superordinated to his own, a superorganism into which he must allow himself to be absorbed, and through participation in which he will come to know the life that transcends death. [pp. 20-2 I]

${ }^{6}$ Although speculative, it seems that feeling of the group would be based on two kinds of experiences. One is experience of the internal functioning of the group; of those activities that constitute its organism. The other is experience of impact from outside, as a function of the group's relation to its environment. Although these two experiences may be felt differently by different members of a group (perhaps systematically in relation to their vantage point), both may be necessary for a coherent experience of the group entity.

7 Although Levy-Bruhl proposed initially that this mode of perception was definitive of primitive mentality and set it apart from civilized mentality, in later writings he retreated from this bold assessment to suggest that this way of seeing was more prominent in the former than in the latter, but present in some degree in both (see, Littleton, 1985).

${ }^{8}$ Writing in a different vein, and of his own modern and mature ego, James (1902) draws a parallel distinction between mundane awareness of things and categories, and a special, seemingly earlier feeling of greater entities and powers. According to James, whereas some things are known by intellectual discernment, others are felt as presences 
at the margins of consciousness. Thus, in a confession of his own philosophizing, he writes:

The whole drift of my education goes to persuade me that the world of our present consciousness is only one out of many worlds of consciousness that exist, and that those other worlds must contain experiences which have a meaning for our life also; and that although in the main their experiences and those of this world keep discrete, yet the two become continuous at certain points and higher energies filter in. (p. 509)

${ }_{9}^{9}$ It is important to distinguish the biological concept of the individual from the sociological concept of the person. The former is a physical fact that is given immediately to perception, the latter is an abstraction of a high order (see, Berger \& Luckmann, r 966; p. 50) and as such not given immediately to perception. To see a person is to see an individual in the broader sociological context of society (see also, Moscovici, 1989). Thus, although we use the two terms interchangeably in this paper, the points about perception pertain most directly to the biological individual.

\section{REFERENCES}

ALDERFER, C. P. ( 1987 ). An intergroup perspective on group dynamics. In J. W. Lorsch (ed.) Handbook of Organizational Behavior. Englewood-Cliffs, NJ: Prentice-Hall.

Alexander, J. C., Geisen, B., MUNCH, R. and SMelser, R. (1987). The Micro-Macro Link. Berkeley, CA: University of California.

AllPORT, F. H. (I927). The Group Fallacy in Relation to Sacial Science. Hanover, NH: Sociological Press.

ALLPORT, F. H. ( 1962 ). A structuronomic conception of behavior: Individual and collective. Journal of Abnormal and Social Psychology, 64, 3-30.

Allison, S. T. and Messick, D. M. ( 1987 ). Group processes and inferences about members. In C. Hendrick (ed.) Group Processes. Newbury Park, CA: Sage.

ARgYle, M. (199I). Cooperation. London: Routledge.

Asch, S. (1952). Social Psychology. Englewood Cliffs, NJ: Prentice-Hall.

BALES, R. F. (1950). Interaction Process Analysis. Chicago: University of Chicago.

BAR-TAL, D. (1990). Group Beliefs. New York: Springer-Verlag.

Barker, L. L., Cegala, D. J., KibleR, R. J. and Wahlers, K. J. (I979). Groups in Process. Englewood Cliffs, NJ: Prentice-Hall.

BARNARD, C. (1938). The Functions of the Executive. Cambridge, MA: Harvard.

BASS, B. M. (1960). Leadership, Psychology, and Organizational Behavior. New York: Harper.

BENEDICT, R. (1 934). Patterns of Culture. Boston: Houghton-Mifflin.

Berger, P. L. and Luckmann, T. (I g66). The Social Construction of Reality. New York: Doubleday.

BION, W. R. (1959). Experiences in Groups and Other Papers. New York: Basic Books.

BLAUner, R. (1964). Alienation and Freedom. Chicago: University of Chicago.

BrodBeck, M. (1958). Methodological individualism: Definition and reduction. Philosophy of Science, 25, I-22.

BROWN, R. J. and TURNER, J. C. ( $198 \mathrm{I}$ ). Interpersonal and intergroup behaviour. In J. C. Turner and H. Giles (eds) Intergroup Behaviour. Oxford: Basil Blackwell.

Buck, R. (1985). Prime theory: An integrated view of motivation and emotion. Psychological Review, 92, 389-4 I3.

CAMPBELL, D. T. (1958). Common fate, similarity, and other indices of the status of aggregates of persons as social entities. Behavioral Science, $3,14-25$. 
CAMPBELl, J. (1972). Myths to Live By. New York: Viking.

CARTwright, C. and Zander, A. (1968). Group Dynamics. New York: Harper \& Row.

CROCKer, J. and LUHTANEN, R. (I990). Collective self-esteem and in-group bias. Journal of Personality and Social Psychology, 58, 6o-67.

Davis, J. H. (I992). Some compelling intuitions about group consensus decisions, theoretical and empirical research, and interpersonal aggregation phenomena: Selected Examples, 1950-1990. Organizational Behavior and Human Decision Processes, 52, 3-38.

DEUTCH, M. ( 1968 ). The effects of cooperation and competition upon group process. In Cartwright, C. and Zander, A. (eds) Group Dynamics. New York: Harper \& Row, pp. $46 \mathrm{r}-482$.

Dur KheIM, E. (r 896/r 932). The Division of Labor in Society. Trans. by G. Simpson. New York: Free Press.

DuRKheIM, E. (I9I5). The Elementary Forms of the Religious Life. London: Allen and Unwin.

FolletT, M. P. (1 937). The process of control. In L. Gulick and S. Urwick (eds) Papers on the Science of Administration. New York: Columbia University.

FreEMAN, L. C. (1992). The sociological concept of "Group": An empirical test of two models. American Journal of Sociology, 98 (1), I 52-66.

Freud, S. ( $1922 /$ I 959). Group Psychology and the Analysis of the Ego. Trans. by J. Strachey. New York: Norton.

Freud, S. (1930/1961). Civilization and Its Discontents. Trans. J. Strachey, I961. New York: Norton.

GalbRaITH, J. (1977). Organization Design. Reading, MA: Addison-Wesley.

Giddens, A. (1979). Central Problems in Social Theory: Action, Structure, and Contradiction in Social Analysis. Berkeley, CA: University of California.

GolembiewsKi, R. T. (1970). The development of the genus 'group'. In Smith, P. B. (ed.) Group Processes. Harmondsworth: Penguin.

GRANOVETTER, M. (1978). Threshold models of collective behavior. American Journal of Sociology, 83, I $420-1443$.

HALBERSTAM, D. ( $198 \mathrm{I}$ ). The Breaks of the Game. New York: Ballantine.

Holldoobler, B. and Wilson, E. O. (I990). Ants. Cambridge, MA: Belknap.

Homans, G. G. (1950). The Human Group. New York: Harcourt.

Homans, G. C. (1987). Behaviourism and after. In A. Giddens and J. Turner (eds) Social Theory Today. Stanford, CA: Polity Press.

INSKO, C. A. and SCHOPLER, J. ( $19^{87}$ ). Categorization, competition, and collectivity. In C. Hendrick (ed.) Group Processes. Newbury Park, CA: Sage.

JAMES, W. (1902). The Varieties of Religious Experience. New York: Longmans, Green and Company.

JANIS, I. ( I 972). Victims of Groupthink. Boston: Houghton-Mifflin.

KATZ, D. and KAHN, R. (1 966). The Social Psychology of Organizations. New York: Wiley.

KIDDER, T. (1981). The Soul of a New Machine. New York: Avon.

KNOWLES, E. S. and BASSETT, R. L. ( 1976 ). Groups and crowds as social entities: Effects of activity, size, and member similarity on nonmembers. Fournal of Personality and Social Psychology, 34, 837-845.

Kroeber, A. L. (191 7). The superorganic. American Anthropologist, 19, 163-213.

LANGER, S. K. (195I). Philosophy in a New Key. Cambridge, MA: Harvard.

LANGER, S. K. ( 1967 ). Mind: An Essay on Human Feeling. Baltimore, MD: Johns Hopkins.

LE BON, G. (1903). The Crowd. New York: Holt.

LEE, R. L. M. (1990). The micro-macro problem in collective behavior: Reconciling agency and structure. Journal for the Theory of Social Behavior, 2o, 213-233. 
Levine, J. M. and Moreland, R. (1990). Progress in small group research. Annual Review of Psychology, 41, 585-634.

LEVY-BRUHL, L. (1931). The solidarity of the individual with his group. In V. F. Calverton (ed.) The Making of Man. New York: Modern Library.

LeVY-BRUhL, L. (1926/1985). How Natives Think. Translated by L. Clare. Princeton, $\mathrm{NJ}$ : Princeton.

LEWIN, K. (1948). Resolving Social Conficts. New York: Harper.

LitTleton, C. S. (1985). Introduction. L. Levy-Bruhl How Natives Think. Princeton, NJ: Princeton.

Mandelbaum, M. (1 955). Societal facts. British Journal of Sociology, 6, 305-3 I 7 .

MARgulis, L. (1981). Symbiosis in Cell Evolution. San Francisco: W. H. Freeman.

MARTIN, P. and LUKE, L. (I99I). Divorce and the wheel theory of love. Journal of Divorce and Remarriage, $\mathbf{5}$ (1-2), 3-21.

MAYHEW, B. H. ( 1980 ). Structuralism versus individualism: Shadow boxing in the dark. Social Forces, 59, 335-375.

MaDougall, W. (1912). Psychology. New York: Henry Holt.

MERTON, R. K. (1957). Social Theory and Social Structure. Glencoe, IL: Free Press.

Messick, D. M. and Mackie, D. M. (1989). Intergroup relations. Annual Review of Psychology, 40, 45-81.

MEYER, P. (I970). If Hitler asked you to electrocute a strange, would you? Esquire, 70 (2): $73+$.

Milgram, S. (1974). Obedience to Authority. New York: Harper \& Row.

Montaigne, M. (1588/1949). Montaigne: Selected Essays. Translated by C. Cotton; revised by W. Hazlitt. New York: Modern Library.

MORELAND, R. L. (1987). The formation of small groups. In C. Hendrick (ed.) Group Processes. Newbury Park, CA: Sage.

Morocco, C. C. (1979). The development and function of group metaphor. Journal for the Theory of Social Behaviour, 9, I 7-28.

Moscovici, S. (1989). Preconditions for explanation in social psychology. European Journal of Social Psychology, 19, 407-430.

Newcomb, T. (1 95I). Social psychological theory. In J. H. Rohrer and M. Sherif (eds) Social Psychology at the Crossroads. New York: Harper.

NozICK, R. (198I). Philosophical Explanations. Cambridge, MA: Belknap.

PARSONS, T. (195I). The Social System. Glencoe, IL: Free Press.

PALMER, S. (I 975). Visual perception and world knowledge. In D. A. Norman, D. E. Rumelhart, and the LNR Research Group. Explorations in Cognition. San Francisco: Freeman.

Ross, R. S. (1989). Small Groups in Organizational Settings. Englewood Cliffs, NJ: PrenticeHall.

RYLE, G. (1949). The Concept of Mind. Chicago: University of Chicago.

SANDELANDS, L. E. (1988). The concept of work feeling. Journal for the Theory of Social Behaviour, 18, 437-458.

SANDELANDS, L. E. and DRAZIN, R. ( 1989 ). On the language of organization theory. Organization Studies, 10, 457-478.

SANDELANDS, L. E. and SRIVATSAN, V. (1993). The problem of experience in the study of organizations. Organization Studies, 14, 1-25.

SANDELANDS, L. E. and STABlEIN, R. (1987). The concept of organization mind. In N. Ditomaso and S. Bachrach (eds) Research in the Sociology of Organizations. Greenwich, CT: JAI Press.

SATA, I. (1988). Bosozoku: Flow in Japanese motorcycle gangs. In M. Csikszentmihalyi and I. Csikszentmihalyi (eds) Optimal Experience. Cambridge: Cambridge University Press. 
Schelling, T. C. (1978). Micromotives and Macrobehaviour. New York: Norton.

SMITH, M. ( I 945). Social situation, social behavior, social group. Psychological Review, 52 (4), 224-229.

STEINER, I. D. (ig86). Paradigms and groups. In L. Berkowitz (ed.) Advances in Experimental Psychology, Vol. 19. Orlando, FL: Academic Press.

Stoodley, B. H. (1962). Society and Self. New York: Free Press.

SzmatkA, J. ( I989). Holism, individualism, reductionism. International Sociology, 4 (2): I $69-186$.

TAJFEL, H. ( 1979 ). Individuals and groups in social psychology. British Journal of Social and Clinical Psychology, 18, I 83-190.

TAJFEL, H. and TURNER, J. (1979). An integrative theory of intergroup conflict. In W. G. Austin and S. Worchel (eds) The Social Psychology of Intergroup Relations. Belmont, CA: Wadsworth.

TAYLOR, D. M. and BROWN, R. J. (1979). Towards a more social social psychology? British Journal of Social and Clinical Psychology, 18, I 73-180.

THOMAs, L. (1974). Lives of a Cell. New York: Viking.

ThOMPSON, J. D. (1967). Organizations in Action. New York: McGraw Hill.

TRIANDIS, H. ( 1989 ). The self and social behavior in differing cultural contexts. Psychological Review, 96, 506-520.

TURNER, J. C. (1985). Social categorization and the self-concept: A social-cognitive theory of group behavior. In E. J. Lawler (ed.) Advances in Group Process (Vol. 2, pp. 77-1 22). Greenwich, CT: JAI Press.

TURNer, R. H. and Killian, L. M. (1987). Collective Behavior, 3e. Englewood Cliffs, NJ: Prentice-Hall.

TURNER, V. (1974). Liminal to liminoid in play, flow, and ritual: An essay in comparative symbology. Rice University Studies, 6o, 53-92.

VON FrISCH, K. (1962). Man and the Living World. New York: Harcourt.

WARRINER, C. K. (1956). Groups are real: A reaffirmation. American Sociological Review, 2I, 549-554.

WEBSTER, M. ( 1973 ). Psychological reductionism, methodological individualism, and large scale problems. American Sociological Review, 38, $25^{8-273 . ~}$

WEGNER, D. M. and Giuliano, T. (1982). The forms of social awareness. In W. Ickes and E. S. Knowles (eds) Personality, Roles, and Social Behavior. New York: SpringerVerlag.

WEICK, K. (1969). The Social Psychology of Organizing. Reading, MA: Addison-Wesley.

Wheeler, W. M. (1939). Essays in Philosophical Biology. New York: Russell \& Russell.

WhITE, H. ( I 992). Identity and Control. Princeton, NJ: Princeton University.

WhITE, L. W. (1947). Culturological vs. psychological interpretations of human behavior. American Sociological Review, 12, 686-698.

Whitehead, A. N. (1924). Process and Reality. New York: Humanities Press.

Whitehead, A. N. (1 934). Nature and Life. Chicago: University of Chicago.

WILDER, D. A. (1977). Perception of groups, size of opposition, and social influence. Journal of Experimental Social Psychology, 13, 253-368.

ZANDER, A. (1982). Making Groups Effective. San Francisco: Jossey-Bass. 